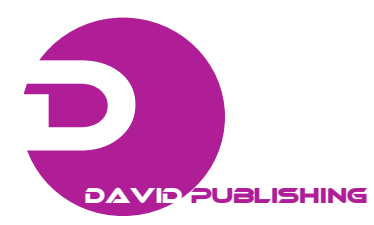

\title{
Influence of RE Modification on Impact Fatigue Property of Low Alloy Wear Resistant Cast Iron
}

\author{
Maishun Qi \\ School of Continuing Education, YanShan University, Qinhuangdao 066004, China
}

Received: August 01, 2014 / Accepted: August 15, 2014 / Published: August 25, 2014.

\begin{abstract}
Aimed at the poor toughness of low alloy wear resistant cast iron, the impact fatigue property of low alloy wear resistant cast iron were measured before and after RE modification, and its microstructure and impact fracture morphology were observed by optical microscope and scanning electron microscope. The results show that RE modification can make the eutectic carbide network in low alloy wear resistant cast iron break up, inhibit the generation and propagation of impact fatigue cracks, and improve the impact fatigue property of low alloy wear resistant cast iron, the effect is more noticeable in case of the RE modification in combination with proper heat treatment.
\end{abstract}

Key words: Low alloy wear resistant cast iron, RE modification, impact fatigue property.

\section{Introduction}

With higher hardness and better wear resistance, low alloy wear resistant cast iron can be used as wear resistant parts in many fields [1-4]. In practice, the wear resistant parts are often required to be subjected to grinding of abrasives and repeated impact action. Therefore, impact fatigue cracks are liable to be generated on their working surfaces, and the parts can become useless due to propagation of these cracks. The morphology of eutectic carbides and the matrix structure in low alloy wear resistant cast iron are the two key factors determining the impact fatigue property. Although RE modification has strong effect of the desulfurization, purification of the melt and refinement of grains [5-7], it has limited effect on the morphology of eutectic carbides [8,9]. On the other hand, the breakage and transition into separate blocks of the continuous network of carbide are spontaneous at high temperature $[10,11]$. Therefore, it can expect that a combination of RE modification and heat treatment can change greatly the morphology of

Corresponding author: Maishun Qi, lecturer, research field: metallic materials. E-mail: Qimaishun@sina.com. eutectic carbide, resulting in improvement of wear resistance of impact fatigue property. In this paper, the effect of RE modification on impact fatigue property of low alloy wear resistant cast iron was studied.

\section{Experiments}

The experimental material was a low alloy wear resistant cast iron, its composition and treatment regime were shown in Table 1 . The material was smelted in a $250 \mathrm{~kg}$ intermediate induction furnace, then poured into two ladles at about $1,450{ }^{\circ} \mathrm{C}$ after deoxidization with aluminum, wherein one of them was modified with RE-Si-Fe alloy modifier. Then, blanks with the size of $\Phi 30 \mathrm{~mm} \times 50 \mathrm{~mm}$ were cast in sand moulds. Heat treatment test was carried out in a KJX-8-13 type electric resistance furnace, and the process parameters are listed in Table 1. The blanks were machined into impact fatigue specimens with the size of $18 \mathrm{~mm} \times 20 \mathrm{~mm}$ and their impact fatigue resistance was determined by single point impact fatigue tester, wherein the impact frequency is 90 times per minute, the impact energy is $9.6 \mathrm{~J}$ per time, and the impact head is an bearing ball with a hardness of HRC 
Table 1 Chemical composition and treatment conditions of specimens (mass fraction, \%).

\begin{tabular}{llllllll}
\hline No. & C & $\mathrm{Si}$ & $\mathrm{Mn}$ & $\mathrm{Cr}$ & $\mathrm{P}$ & $\mathrm{S}$ & Treatment conditions \\
\hline 1 & 2.13 & 0.72 & 1.54 & 1.57 & 0.034 & 0.031 & Cast \\
2 & 2.13 & 0.72 & 1.54 & 1.57 & 0.034 & 0.031 & $0.20 \%$ RE modification \\
3 & 2.13 & 0.72 & 1.54 & 1.57 & 0.034 & 0.031 & $0.20 \%$ RE modification + normalizing at $970{ }^{\circ} \mathrm{C}$ for $3 \mathrm{~h}$ \\
\hline
\end{tabular}

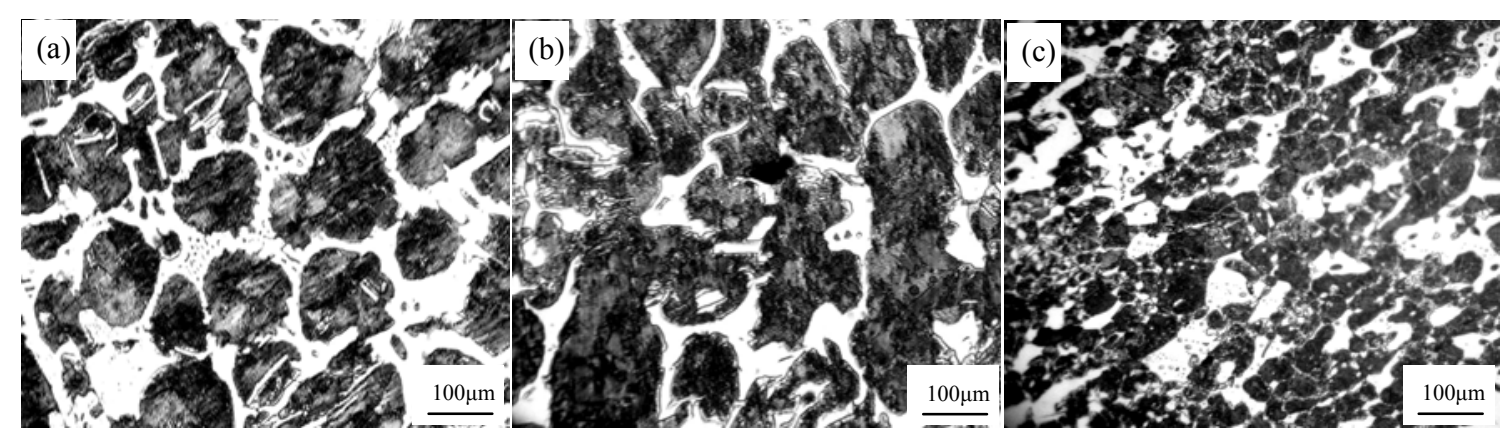

Fig. 1 Microstructure of low alloy wear resistant cast iron at different states. (a) As-cast; (b) RE modification and (c) RE modification and heat treatment.

63. The surface of the specimen to be tested was ground and polished, and then fixed in the test position. In the test, the impact duration for a crack about $0.2 \mathrm{~mm}$ long produced on the testing surface was referred to be as the impact fatigue resistance $(\mathrm{N})$, and then, the testing surface was further impacted 1,000 times. During the whole testing process, the crack length was recorded every 200 times, and the average crack length value was made to be as the crack propagation rate. The morphology of carbides, the generation and propagation of the cracks, these values are averages of five fields of vision measured results under a microscope with 100 magnification. The microstructure and appearance of desquamated surface were observed by NEOPHOT21 optical microscope and KYKY-2800 scanning electron microscope.

\section{Results and Discussion}

3.1 The Morphology of Carbides and the Impact Fatigue Property

The morphologies and distributions of carbide with different treatments are shown in Fig. 1. It can be seen that, for specimen without RE modification, the distribution of eutectic carbides is continuous and netlike, while for specimen with RE modification, the carbides can maintain their netlike feature despite of the occurrence of local necking-down joint and broken net. As for specimen with RE modification and heat treatment, the netlike feature of eutectic carbide disappeared, and carbides are distributed in the form of independent blocks. Meanwhile, there emerged some tiny granular carbides in the matrix. So, it can be concluded that RE modification and heat treatment can enhance the breakage of the netlike carbides.

Because of the larger RE atomic radius as compared with that of $\mathrm{Fe}$ atom, $\mathrm{RE}$ atom has lower solid solubility. For this reason RE atoms are apt to be enriched on the new carbide surfaces and inhibit preferential growth of carbide, which makes it difficult for the carbide to form a closed net, and leads to the occurrence of broken reticulate carbide. It is thermodynamically certain that the distribution of eutectic carbide transforms from netlike to block at high temperature $[10,11]$. The transformation is dependant on the dissolution of carbide as well as diffusion and precipitation of carbon atoms. Comparatively, the weak section of the netlike carbide would be most easily ruptured. The effect of RE addition behaves in three aspects. Firstly, RE addition can increase the weak sections of the reticulate carbide; secondly, RE atoms dissolving into carbides can induce crystal distortion and decrease stability of the 
carbide [12]; and, finally, because the atomic radius of $\mathrm{RE}$ is $25 \%$ larger than that of $\mathrm{Fe}$ atom, the distortion will become severer, and there will be more defects in the matrix. These effects would accelerate dissolution of carbide and diffusion of carbon atom at high temperature, thus resulting in the melting induced breakage and the conglomeration of the reticulate carbides, as well as the granular carbides in the matrix.

Table 2 shows the test results of impact fatigue property. It can be seen that specimen with a combination of RE modification and heat treatment exhibits the highest impact fatigue resistance $(\mathrm{N})$, the fewest total number of cracks (n) and the lowest crack propagation rate $(\mathrm{v})$, therefore, it has the best impact fatigue resistance, while specimen with either the RE modification, whose testing results are very close, takes the second place. The impact fatigue resistance for specimen without any modification is the worst. Compared with the results for specimen without RE modification, the impact fatigue resistance of the specimen with a combination of RE modification and heat treatment increases by $102.17 \%$, and the crack propagation rate decreases by $55.63 \%$, which indicates that RE modification followed by heat treatment can effectively improve the impact fatigue resistance of the wear resistant white cast iron.

\subsection{Relationship between the Impact Fatigue Cracks and the Carbides}

Fig. 2 shows places of impact fatigue crack initiation. It can be observed that the impact fatigue crack is mainly generated at and propagated along the interface between eutectic carbides and matrix. The cracks not only propagate separately but also link each other, and finally, join to form main cracks. Then, the main cracks propagate through the matrix and link to other cracks. From SEM observation of ruptured surfaces (Fig. 3), it can be seen that there exist secondary cracks at carbides as well as interface between eutectic carbide and matrix. The ruptured surface of as-cast specimen without any RE modification shows mainly inter granular fractured feature, but tear ridge and dimple appear in some small regions of the specimen with RE modification and heat treatment, which indicates that more energy is needed when fractured, the specimen with RE modification and heat treatment is better than that of specimen without RE modification. The reason for the phenomenon above is the difference in the morphology and distribution of carbide.

\section{Discussion}

According to the results mentioned above, carbides are the main generating places and propagation passages for impact fatigue cracks. With high brittleness, carbides are very liable to be broken under the action of repeated impact load. Moreover, the difference in the ability of plastic deformation between carbides and matrix leads to the occurrence of stress concentration and generation of micro-cracks more easily around carbides. Once cracks are generated, they will propagate rapidly along the interfaces between carbides and matrix under the action of repeated impact load. Therefore, the morphology and distribution of carbides are the main factors affecting specimen's impact resistance. RE modification and heat treatment can make the carbides in the specimen transforming from continuous nets to separate blocks, which can protect the matrix's continuity and relax stress concentration, so it can delays the generating time for the fatigue cracks and decrease the crack's generation rate. As for the propagation passages of cracks, it can

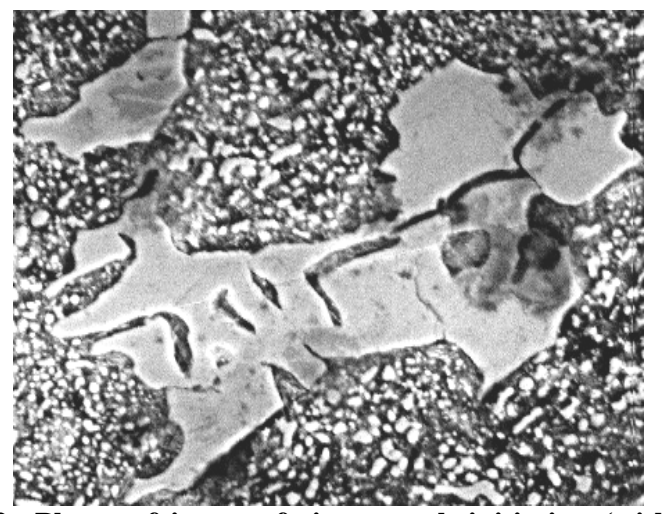

Fig. 2 Places of impact fatigue crack initiation (with RE modification). 
Table 2 Results of impact fatigue property.

\begin{tabular}{lllllll}
\hline \multirow{2}{*}{$\begin{array}{l}\text { No. Total number of } \\
\text { cracks }(\mathrm{n} / \text { piece })\end{array}$} & \multicolumn{3}{c}{ Number of cracks of different size } & Impact fatigue resistance & $\begin{array}{l}\text { Crack propagation rate } \\
\left(\mathrm{v} \times 10^{-2} / \mathrm{mm} \cdot \mathrm{N}\right)\end{array}$ \\
\cline { 2 - 6 } & $>100 \mu \mathrm{m}$ & $50 \sim 100 \mu \mathrm{m}$ & $<50 \mu \mathrm{m}$ & $\left(\mathrm{N} \times 10^{3} /\right.$ times $)$ & 9.51 \\
2 & 13 & 3 & 5 & 5 & 1.27 & 7.65 \\
3 & 11 & 2 & 4 & 5 & 1.84 & 4.22 \\
\hline
\end{tabular}

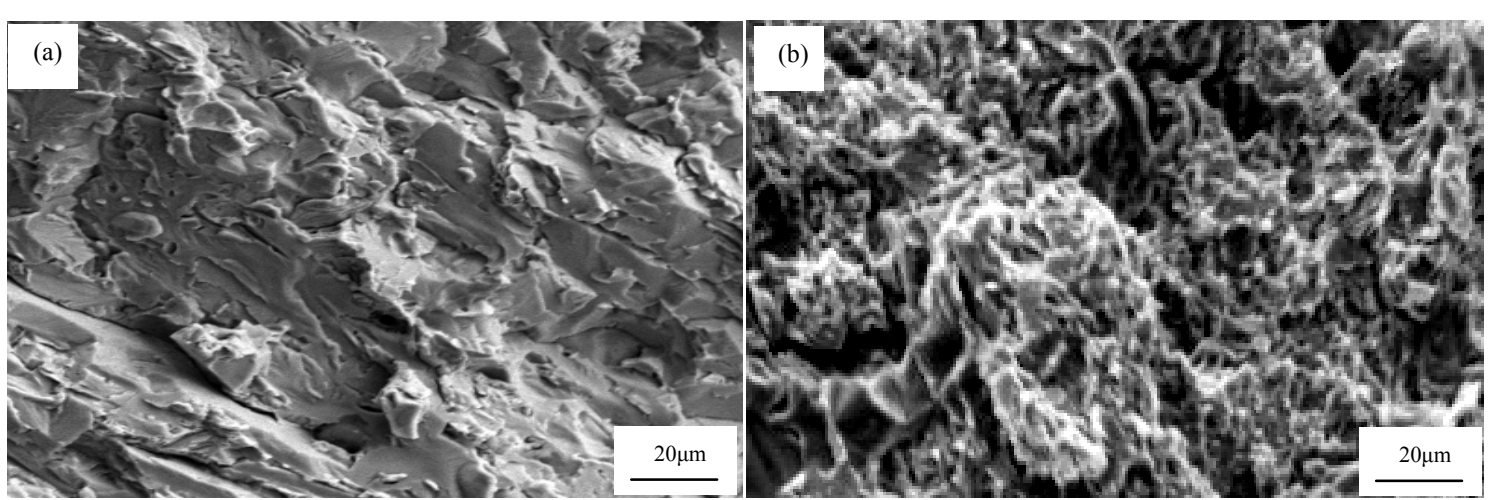

Fig. 3 Morphology of impact fractured specimen. (a) As-cast and (b) RE modification and heat treatment.

be seen that cracks preferably propagate along grain boundaries and phase boundaries, because the strength of grain boundaries or phase boundaries is lower than that of single-phase grains. The addition of RE elements can refine the grains, decrease inclusions at grain boundaries and phase boundaries, and improve strength of grain boundaries and phase boundaries. The transition of carbides from continuous nets to separate blocks can reduce the crack's propagation area along the interface of carbides. Therefore, if cracks propagate continuously, they must traverse the matrix so as to further propagate from one carbide block to another neighboring carbide block. The matrix has good plasticity, when cracks propagate through it, it can produce plastic deformation, and, accordingly, absorb deformation work. This will consume much energy and relax stress concentration at crack tip, which leads to the increase in curvature radius and dullness of crack's tips, thereby making the crack propagation more difficult. Furthermore, fine granular carbides in the matrix prevent from motion of dislocations, which results in the increase of the resistance of crack propagation [13]. In addition, RE modification has strong effect of desulfurization and purification of the melt, so that plasticity of the experimental material will be increased, and accordingly, crack's propagation rate reduced. Therefore, it can be seen that RE modification can defer crack forming time, reduce crack propagation rate and increase impact fatigue resistance effectively. However, specimens with either RE modification, the morphology and distribution of carbides can be modified by a very limited extent, while the compound effect of the two treatments mentioned above can greatly improve the specimen's impact fatigue property.

\section{Conclusions}

Eutectic carbide is the main location and passage for generation and propagation of the impact fatigue cracks in low alloy wear resistant cast iron, RE modification can improve the morphology of eutectic carbides and make the carbides transform from continuous network to separate blocks, inhibit the generation and propagation of impact fatigue cracks, and improve impact fatigue resistant property of the cast iron, which is more evident in case of RE modification followed heat treatment.

Moreover, after $0.20 \%$ RE modification and normalizing at $970{ }^{\circ} \mathrm{C}$ for $3 \mathrm{~h}$, the impact fatigue property of low alloy wear resistant cast iron is 
increased by $102.17 \%$.

\section{Acknowledgments}

This work was supported by Qinhuangdao Science and Technology Research and Development Program, China. (No.201302A034)

\section{References}

[1] B. Vlaovic, Z. Acimovic-Pavlovic, The correlation between the chemical composition, structure and properties of low chromium white iron casted in water-cooled metal moulds, Metalurgia International 17 (7) (2012) 86-89.

[2] S.G. Banadkouki, S. Mehranfar, Wear behavior of a modified low alloy as cast hardening white iron, ISIJ International 52 (11) (2012) 2096-2099.

[3] R. Huang, R.L. Ma, Z.L. Lu, Y. Zhang, Effect of alloying elements on the corrosion wear behaviors of low chromium cast iron, Materials Science Forum 695 (2011) 397-400.

[4] S. Mehranfar, S.G. Banadkouki, M. Kallantar, M.M. Yazdi, Improved color metallography for a low alloy hardened white cast iron, ISIJ International 52 (9) (2012) 1649-1654.

[5] Y.W. Son, Q.S. Luo, Q.D. Chen, Effect of RE-B modification on the strength and toughness of $30 \mathrm{CrMn}_{2} \mathrm{Si}$ cast steel, Journal of Material Science 29 (6) (1994)
1492-1494.

[6] A.B. Sergeev, B.M. Starostin, Y.V. Kofinana, Technology for microalloying of steel andalloys, Metallurg 3 (1996) 31-32.

[7] Q.X. Yang, B. Liao, J.H. Liu, Effect of rare earth elements on austente growth dynamics of steel $60 \mathrm{CrMnMo}$, Journal of rare earths 16 (3) (1998) 274-276.

[8] L.M. Chang, J.H. Liu, R.J. Zhang, Q.X. Yang, Effect of rare earth elements on dynamics of thermal fatigue crack's propagation in low alloy white cast iron, Journal of Rare Earths 22 (Suppl) (2004) 146-149.

[9] A. Bedolla-Jacuinde, S.L. Aguilar, C. Maldonado, Eutectic modification in a low-chromium white cast iron by a mixture of titanium, rare earths, and bismuth: Part II. Effect on the wear behavior, Journal of Materials Engineering and Performance 14 (3) (2005) 301-306.

[10] Q. Ma, B.C. Liu, Z.C. Wu, Study of the continuous morphological changes of carbide during high temperature holding of Fe-C alloys, Iron and Steel 29 (5) (1994) 47-48.

[11] Q. Ma, Z.C. Wu. Dissolution and granulation of eutectic carbide during heat treatment of white cast iron, Journal of Iron and Steel Research 2 (1) (1990) 63-65.

[12] S.Q. Wang, Q.C. Jiang, X.H. Cui, Effect of RE on granulation of eutectic carbide in ledeburite steel, Journal of the Chinese Rare Earth Society 16 (3) (1998) 242-246.

[13] Z. Feng, D.J. Liu, Z.Y. Qin, Investigation on high concentration carburizing and the resultant property, Hot Working Technology 112 (6) (1994) 11-13. 